\title{
Cinnamon Essential Oil Nanocellulose-Based Pickering Emulsions: Processing Parameters Effect on Their Formation, Stabilization, and Antimicrobial Activity
}

\author{
Alana Gabrieli de Souza (D), Rafaela Reis Ferreira, Elisa Silva Freire Aguilar, Leonardo Zanata \\ and Derval dos Santos Rosa*D
}

check for updates

Citation: Souza, A.G.d.; Ferreira, R.R.; Aguilar, E.S.F.; Zanata, L.; Rosa, D.d.S. Cinnamon Essential Oil Nanocellulose-Based Pickering Emulsions: Processing Parameters Effect on Their Formation, Stabilization, and Antimicrobial Activity. Polysaccharides 2021, 2, 608-625. https://doi.org/10.3390/ polysaccharides 2030037

Academic Editor: Hyun Chan Kim

Received: 2 July 2021

Accepted: 22 July 2021

Published: 3 August 2021

Publisher's Note: MDPI stays neutral with regard to jurisdictional claims in published maps and institutional affiliations.

Copyright: (c) 2021 by the authors. Licensee MDPI, Basel, Switzerland. This article is an open access article distributed under the terms and conditions of the Creative Commons Attribution (CC BY) license (https:// creativecommons.org/licenses/by/ $4.0 /)$.
Centro de Engenharia, Modelagem e Ciências Sociais Aplicadas, CECS/Universidade Federal do ABC (UFABC), Avenida dos Estados, 5001, Santo André CEP 09210-580, SP, Brazil; alana_gs@live.com (A.G.d.S.); rafaela_reisf@hotmail.com (R.R.F.); eaisaguilar@gmail.com (E.S.F.A.); lzanata82@gmail.com (L.Z.)

* Correspondence: dervalrosa@yahoo.com.br

\begin{abstract}
This work aimed to prepare nanocellulose-based Pickering emulsions using cinnamon essential oil. Different formulations were investigated by varying the preparation time, homogenization speed, oil and nanocellulose concentration, and morphology. The emulsions were first characterized by droplet size, morphologies, and storage stability. The Design of Experiments (DoE) was used to evaluate the parameter's effects on the emulsions' stability, and the emulsions with optimum particle size and stability were evaluated by antimicrobial activity. The more stable emulsions required higher energy in the system to obtain efficient emulsification. The cellulose nanocrystal (CNC) emulsions showed a $30 \%$ oil volume as a constant to obtain a low creaming index (34.4\% and $42.8 \%)$ and zeta potential values around $-29 \mathrm{mV}$, indicating an electrostatic stabilization. The cellulose nanofiber (CNF) emulsions showed $100 \%$ stability after a month using a $20 \%$ oil volume as a constant and Zeta potential values around $-15 \mathrm{mV}$, indicating a steric stabilization. CNF-emulsions' inhibition halos for Bacilus subtilis were $30.1 \pm 3.7 \%$ smaller than those found in CNC-emulsions $(65 \pm 2.9 \mathrm{~mm})$, while Pseudomonas aeruginosas almost do not present differences in the inhibition halos. These results suggest that the nanocellulose morphology may promote a regulation on the EO migration to the medium, as well that this migration ratio does not affect the bacteria.
\end{abstract}

Keywords: cinnamon cassia; cellulose nanocrystals; cellulose nanofibers; design of experiments; antibacterial activity

\section{Introduction}

Essential oils (EOs) are a popular and widely used class of antimicrobial and antioxidant substances used in various applications. EOs have a history of use that dates back to the dawn of humanity, playing a relevant role in folk medicine, and hygienic and therapeutic uses. According to ISO DIS9235.2 (International Organization for Standardization), an $\mathrm{EO}$ is "a product prepared by water or steam distillation or by mechanical processing of citrus peel or by dry distillation of natural materials" [1]. These natural compounds can be found in a wide variety of plants and microorganisms. The active compounds present in EOs are mainly monoterpenes (limonene, sabinene, P-cymene), monoterpenoids (thymol, carvacrol, citronella, and borneol), and phenylpropanoids (cinnamaldehyde, vanillin, eugenol, and safrol) [2]. This compounds' proportion varies according to the material source and its characteristics, such as geographic origin, development stage, year season, plant age, among others [3]. This class of materials is listed as Generally Recognized as Safe (GRAS) by the FDA USA in 21 e-CFR (electronic Code of Federal Regulation) part 182.20 [4-6]. There are various essential oils already used, and the cinnamon EO has more than 160 separate and identified components, such as terpenoids and phenylpropanoids, with cinnamaldehyde being the most representative component $[7,8]$. 
Due to the essential oils' bioactive properties, there is a growing demand for their use in different applications, such as alternative medicine, cosmetics, cleaning products, food, and packaging. However, due to their chemical structure and intrinsic properties, EOs have high volatility, hydrophobicity, photosensitivity, high susceptibility to oxidation, intense aroma, low stability, and poor solubility [9]. In addition, some studies have demonstrated cinnamaldehyde instability when exposed to air since reactive unsaturated aldehyde is easily oxidized to cinnamic acid, which causes volatility and instability. Decomposition can also occur before the essential oil can perform its bactericidal activity, requiring stabilization under appropriate conditions [10,11].

A promising strategy to stabilize the essential oils is the incorporation of nanoparticles to prepare a colloidal system with superior stability and ease of application, the so-called Pickering emulsions. In this system, solid particles are adsorbed at the oil/water interface, altering the free energy of the system and the balance of surface energies. In addition, the particles prevent phase separation and increase emulsion stability through mechanical and steric protections that prevent droplets' coalescence [12,13]. Previous studies investigate numerous particles to stabilize oil-in-water emulsions, such as nanoplates [14], chitin nanocrystals [15], multiwalled carbon nanotubes [16], hydrophobically modified nanocellulose [17], fibrous nanocellulose [18], protein [19], nanorods [20], and others.

Nanocellulose has received extensive attention due to its variable morphology and surface chemistry [21]. The morphology and size of the nanoparticles change the emulsion rheology, capillary forces, aspect ratio, and ordering effects of the particles around the droplets (interface configuration), making it possible to modulate the emulsion characteristics to obtain a highly stable configuration [22]. These nanoparticles can be found in the following two main morphologies: nanocrystals (CNC) or nanofibers (CNF). Both morphologies are good options for stabilizing interfaces between different polarity liquids, as they have an amphiphilic nature and are anisotropic, requiring low levels of solids for percolation, resulting in high viscosity self-assembled gels and structures [23,24]. However, the emulsion stability depends not only on the solid phase characteristics but also on the essential oil and preparation parameters. Sanchez-Salvador et al. investigated the use of cellulose microfibers (CMF) as a solid phase in oil in water emulsion [25]. The authors used different $\mathrm{O} / \mathrm{W}$ ratios and $\mathrm{CMF}$ concentrations, and the results indicated that the lower $\mathrm{O} / \mathrm{W}$ ratios generated unstable emulsions with an oil phase on the top of the emulsion. Similarly, Mikulcová et al. prepared emulsions stabilized with nanocellulose, a varying oil concentration and CNC or CMF concentrations [26]. The authors reported that high oil and low cellulose concentrations resulted in reasonably good stability for 8 weeks of storage. However, the authors did not vary the processing parameters in both works, such as homogenization speed or time.

Moreover, the literature reports several works using nanocellulose as a solid phase in Pickering emulsions with different essential oils [18,27-29]. Yu et al. prepared CNCstabilized clove oil Pickering emulsions and observed high stability to coalescence [30]. However, the emulsions showed flocculation and creaming, probably due to the poor surface coverage at the $\mathrm{O} / \mathrm{W}$ interface. Shin et al. developed CNC-stabilized thyme white Pickering emulsions with high stability and bactericidal and larvicidal activities [31]. Seo et al. prepared CNC-stabilized Pickering emulsions of nutmeg and massoia essential oils with high stability for 10 storage days and potential larvicide against Aedes albopictus [32] This work aimed to investigate the influence of process parameters and nanocellulose morphology on stabilizing cinnamon essential oil via the Pickering emulsion. The investigated parameters were processing time, essential oil concentration, homogenization speed, nanocellulose morphology, and nanocellulose concentration, which were evaluated through size, morphology, and storage time. The Design of Experiments (DoE) was used to evaluate each parameter's effects on the emulsions' characteristics, and their influence on emulsion instability and droplet size, individually and in pairs. The most stable emulsions were characterized by the Zeta potential and antimicrobial effect against B. subtillis and $P$. aeruginosa. 


\section{Materials and Methods}

\subsection{Materials}

Cellulose nanocrystals (CNC) $(2.0 \pm 0.8 \mu \mathrm{m}$ in length and $131.1 \pm 29.6 \mathrm{~nm}$ in diameter, $\mathrm{L} / \mathrm{D}=15, \zeta$ potential of $-33.0 \pm 1.0 \mathrm{mV}$ ) were prepared and characterized according to our previous works $[33,34]$. Cellulose nanofibrils (CNF) $(4.0 \pm 1.0 \mu \mathrm{m}$ in length and $66.3 \pm 20.5 \mathrm{~nm}$ in diameter, $\mathrm{L} / \mathrm{D}=60, \zeta$ potential of $-33.2 \pm 3.2 \mathrm{mV}$ ) were donated by Suzano Papel e Celulose (São Paulo, Brazil) [35]. Cinnamon essential oil (Cinnamomum cassia, CAS Number 84961-46-6, main compound: cinnamaldehyde $(80 \%)$ ) was provided by Ferquima Indústria e Comércio Ltd.a. (São Paulo, Brazil). Microbiological Nutrient broth and Agar nutrient were supplied by HIMEDIA (Mumbai, India). Microorganisms' seeds were provided by Adolfo Lutz Institute (São Paulo, Brazil).

\subsection{Methods}

The CNC or CNF were previously dispersed, and the cinnamon essential oil was added to this solution. The mixture was homogenized in an Ultra-Turrax Blender (IKA T25 model, IKA Werke, Staufen, Germany). The investigated parameters were selected, aiming to establish maximum and minimum values for adequate emulsion stability. The selected parameters were nanocellulose morphology (CNC or $\mathrm{CNF})$, nanocellulose concentration $(0.5$ or $1 \mathrm{wt} \%)$, processing time ( 3 or $7 \mathrm{~min})$, homogenization speed $(10,000 \mathrm{rpm}$ or $12,000 \mathrm{rpm})$, and essential oil concentration $(20$ or $30 \% v / v)$. Table 1 shows some works that present the different parameters used in the literature. The parameters selected in this paper were based on an extensive literature search, mainly the references of Table 1 , associated with several experimental tests.

Table 1. Preparation parameters of several Pickering emulsions from published articles were used to select this paper's adopted methodology.

\begin{tabular}{|c|c|c|c|c|c|c|c|}
\hline Reference & Oil & Speed & O/W Ratio & Time & $\begin{array}{l}\text { Cellulose } \\
\text { Morphology }\end{array}$ & $\begin{array}{c}\text { Cellulose } \\
\text { Concentration }\end{array}$ & Stability \\
\hline \multirow{2}{*}{ [35] } & Ho wood & $5000 \mathrm{rpm}$ & $20 / 80$ & $40 \mathrm{~min}$ & CNF & $0.75 w t^{\circ} \%$ & $50 \%$ \\
\hline & Cinnamon & $5000 \mathrm{rpm}$ & $20 / 80$ & $40 \mathrm{~min}$ & CNF & $0.75 w \mathrm{t} \%$ & $65 \%$ \\
\hline$[30]$ & Clove oil & $22,000 \mathrm{rpm}$ & $10 / 90$ & $1 \mathrm{~min}$ & $\mathrm{CNC}$ & $\begin{array}{c}0.1,0.25 \text {, and } \\
0.5 \mathrm{wt} \%\end{array}$ & "good" \\
\hline$[36]$ & Dodecane & $11,000 \mathrm{rpm}$ & $10 / 90$ & $4 \mathrm{~min}$ & $\mathrm{CNF}$ & $\begin{array}{c}0.05,0.1,0.15 \\
\text { and } 0.2 \mathrm{wt} \%\end{array}$ & "high" \\
\hline [27] & Palm oil & $10,000 \mathrm{rpm}$ & $50 / 50$ & $3 \mathrm{~min}$ & CNF & $1 \mathrm{wt} \%$ & "high" \\
\hline [37] & $\begin{array}{l}\text { Corn oil, } \\
\text { Silicone oil, } \\
\text { and } \\
\text { Limonene }\end{array}$ & $15,000 \mathrm{rpm}$ & $25 / 75$ & $3 \mathrm{~min}$ & $\begin{array}{l}\text { Semicrystalline } \\
\text { cellulose } \\
\text { oligomers }\end{array}$ & $\begin{array}{c}0.2,0.4,0.6,0.8 \\
1.0, \text { and } \\
1.2 \mathrm{wt} \%\end{array}$ & $\begin{array}{c}\text { Between } 40 \\
\text { and } 100 \%\end{array}$ \\
\hline$[38]$ & Dodecane & $10,000 \mathrm{rpm}$ & $\begin{array}{c}\text { From } 10 / 90 \\
\text { to } 50 / 50\end{array}$ & $2 \mathrm{~min}$ & $\mathrm{CNF}$ & $0.1-0.5 w t \%$ & $\begin{array}{c}\text { Between } 60 \\
\text { and } 100 \%\end{array}$ \\
\hline [12] & Dodecane & $24,000 \mathrm{rpm}$ & $\begin{array}{l}20 / 80 \text { and } \\
35 / 65\end{array}$ & $2 \mathrm{~min}$ & $\mathrm{CNF}$ & $\begin{array}{r}0.1,0.5,1.0 \\
\text { and } 1.5 \mathrm{wt} \%\end{array}$ & $\begin{array}{l}\text { Low oil con- } \\
\text { centration -> } \\
\text { low stability }\end{array}$ \\
\hline [39] & Dodecane & $12,000 \mathrm{rpm}$ & $10 / 90$ & $3 \mathrm{~min}$ & Microcrystalline & $0.5-2 w t \%$ & "high" \\
\hline [23] & Almond oil & $20,000 \mathrm{rpm}$ & $30 / 70$ & $5 \mathrm{~min}$ & Cationic CNF & 0.5 and $1 \mathrm{wt} \%$ & $99 \%$ \\
\hline [40] & Palm olein & $10,000 \mathrm{rpm}$ & $20 / 80$ & $5 \mathrm{~min}$ & $\mathrm{CNC}$ & $\begin{array}{c}0.15 \text { and } 0.3 \\
\text { wt } \%\end{array}$ & $100 \%$ \\
\hline [41] & Olive oil & $12,000 \mathrm{rpm}$ & $\begin{array}{c}10 / 90,30 / 70 \\
\text { and } 50 / 50\end{array}$ & $2 \mathrm{~min}$ & $\mathrm{CNF}$ & $\begin{array}{r}0.05,0.1,0.2, \\
\text { and } 0.25 \mathrm{wt} \%\end{array}$ & $\begin{array}{c}\text { Between } 60 \\
\text { and } 100 \%\end{array}$ \\
\hline
\end{tabular}

Figure 1 illustrates the adopted methodology, indicating the selected processing parameters. 


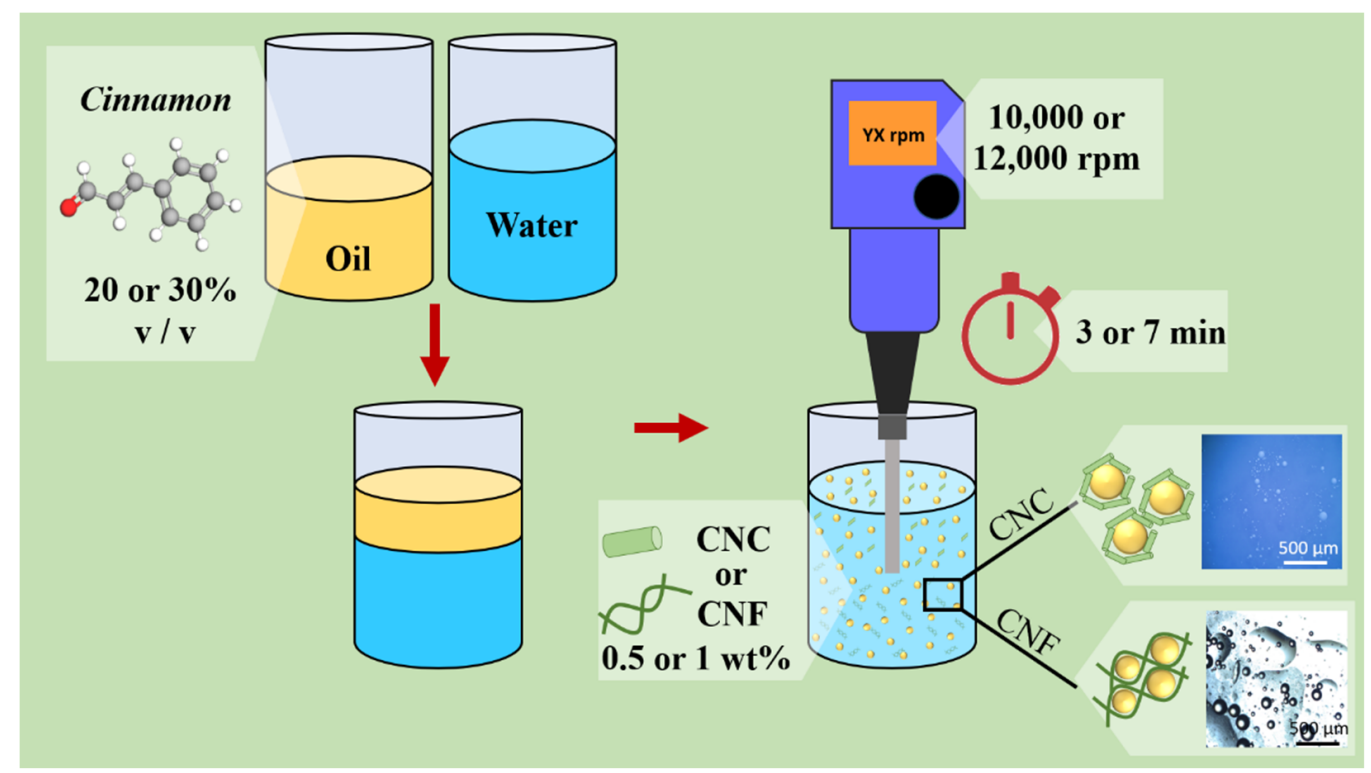

Figure 1. Illustrative representation of the adopted methodology and the selected processing parameters varied in this work.

These work samples were selected using an experimental design through the DesignExpert $^{\circledR}$ software (Trial version 12.0.0, Stat-Ease, Inc., Minneapolis, MN, USA). For this, a Regular two-level factorial design was conducted, with the $2^{5-1}$ configuration. Table 2 presents the samples' nomenclature. Design-Expert ${ }^{\circledR}$ was also used for the statistical experimental design.

Table 2. Adopted samples nomenclature, where the green color represents the CNC-stabilized emulsions, and the red color represents the CNF-stabilized Pickering emulsions.

\begin{tabular}{|c|c|}
\hline Nomenclature & Processing Conditions \\
\hline $\mathrm{PE}^{1}-1 \mathrm{CNC}-12-30-3$ & $1 \% \mathrm{CNC}, 12,000 \mathrm{rpm}, 30 \%$ oil, $3 \mathrm{~min}$ \\
\hline PE-0.5CNC-10-30-3 & $0.5 \% \mathrm{CNC}, 10,000 \mathrm{rpm}, 30 \%$ oil, $3 \mathrm{~min}$ \\
\hline PE-1CNC-10-20-3 & $1 \% \mathrm{CNC}, 10,000 \mathrm{rpm}, 20 \%$ oil, $3 \mathrm{~min}$ \\
\hline PE-0.5CNC-12-20-3 & $0.5 \% \mathrm{CNC}, 12,000 \mathrm{rpm}, 20 \%$ oil, $3 \mathrm{~min}$ \\
\hline PE-1CNC-10-30-7 & $1 \% \mathrm{CNC}, 10,000 \mathrm{rpm}, 30 \%$ oil, $7 \mathrm{~min}$ \\
\hline PE-0.5CNC-12-30-7 & $0.5 \% \mathrm{CNC}, 12,000 \mathrm{rpm}, 30 \%$ oil, $7 \mathrm{~min}$ \\
\hline PE-1CNC-12-20-7 & $1 \% \mathrm{CNC}, 12,000 \mathrm{rpm}, 20 \%$ oil, $7 \mathrm{~min}$ \\
\hline PE-0.5CNC-10-20-7 & $0.5 \% \mathrm{CNC}, 10.000 \mathrm{rpm}, 20 \%$ oil, $7 \mathrm{~min}$ \\
\hline PE-1CNF-12-30-3 & $1 \%$ CNF, $12,000 \mathrm{rpm}, 30 \%$ oil, $3 \mathrm{~min}$ \\
\hline PE-0.5CNF-10-30-3 & $0.5 \% \mathrm{CNF}, 10,000 \mathrm{rpm}, 30 \%$ oil, $3 \mathrm{~min}$ \\
\hline PE-1CNF-10-20-3 & $1 \% \mathrm{CNF}, 10,000 \mathrm{rpm}, 20 \%$ oil, $3 \mathrm{~min}$ \\
\hline PE-0.5CNF-12-20-3 & $0.5 \% \mathrm{CNF}, 12,000 \mathrm{rpm}, 20 \%$ oil, $3 \mathrm{~min}$ \\
\hline PE-1CNF-10-30-7 & $1 \% \mathrm{CNF}, 10,000 \mathrm{rpm}, 30 \%$ oil, $7 \mathrm{~min}$ \\
\hline PE-0.5CNF-12-30-7 & $0.5 \% \mathrm{CNF}, 12,000 \mathrm{rpm}, 30 \%$ oil, $7 \mathrm{~min}$ \\
\hline PE-1CNF-12-20-7 & $1 \% \mathrm{CNF}, 12,000 \mathrm{rpm}, 20 \%$ oil, $7 \mathrm{~min}$ \\
\hline PE-0.5CNF-10-20-7 & $0.5 \% \mathrm{CNF}, 10,000 \mathrm{rpm}, 20 \%$ oil, $7 \mathrm{~min}$ \\
\hline
\end{tabular}

${ }^{1} \mathrm{PE}$ is an abbreviation for Pickering Emulsion.

\subsection{Characterization}

\subsubsection{Optical Microscopy}

The droplet microstructures were analyzed using a Leica DM KM optical microscope (Leica Microsystems GmbH, Wetzlar, Germany). An emulsion droplet was added to a glass slide, and representative images were obtained. The droplet diameters were measured using the ImageJ software as an average number of 120 droplets. 


\subsubsection{Stability under Storage}

Fresh samples were added to glass tubes and stored at room temperature for a month. The emulsion stability (\%) was measured on days $0,10,15,21$, and 30 in triplicate. The creaming index $(\mathrm{CI})$ was calculated following Equation (1), where $H_{\text {cream }}$ is the cream layer height, and $H_{t}$ is the total height.

$$
C I=\frac{H_{\text {cream }}}{H_{\text {total }}} \times 100
$$

\subsubsection{Stability toward Shear}

Shear stability was evaluated using emulsion centrifugation. After two hours of preparation, the emulsions were centrifuged (Thermo Scientific 75,002,42, Thermo Fisher Scientific, Waltham, MA, USA) for $1 \mathrm{~min}$ at 12,000 rpm [12]. The emulsions were evaluated visually, and the stability was calculated according to Equation (2) [42], where $E E$ is the emulsification efficiency, $H_{E}$ is the emulsified phase height, and $H_{T}$ is the total height of the sample.

$$
E E=\frac{H_{E}}{H_{T}} \times 100
$$

\subsubsection{Zeta Potential}

The Zeta $(\zeta)$ potential was measured in Zetasizer Nano ZS equipment (Malvern Instruments, Malvern, UK), which determines the values using electrophoretic mobility measurements and converts the values using the Helmholtz-Smoluchowski equation. The emulsions were diluted at a concentration of $0.05 \%(v / v)$.

\subsubsection{Antimicrobial Tests}

Antibacterial activity tests were conducted based on the methodology proposed by JIS 2010 (Japanese Industrial Standard) [43] and previously applied [44]. The procedures are described briefly. Pre-seeded and adjusted to $10^{5} \mathrm{CFU} \cdot \mathrm{mL}^{-1}$ (counting forming units in Nutrient Broth), Bacillus subtillis (Caron Beta A 155) and Pseudomonas aeruginosa (ATCC 10145) were spread-plate inoculated in $90 \mathrm{~mm}$ diameter plates, using Agar nutrient medium. For the inhibition zone assays, $10 \mu \mathrm{L}$ of the emulsions were placed in contact with the inoculum plates, which were incubated at $30 \pm 0.5^{\circ} \mathrm{C}$ to B. subtilis and $36 \pm 0.5{ }^{\circ} \mathrm{C}$ to $P$. aeruginosa, for $48 \mathrm{~h}$ with $85 \%$ humidity. The inoculums viability was confirmed via pour-plate method on Agar nutrient, as the positive control.

\subsubsection{Statistical Analysis}

The measurements were carried out at least in triplicate and reported as mean \pm standard deviation. One-way analysis of variance (ANOVA) was applied, and the Tukey test was used to evaluate the significant difference between samples, using PAST software (version 4.03) and a confidence level of $95 \%$.

\section{Results and Discussion}

Figure 2 shows the Pickering emulsions developed in this work. The CNC stabilized emulsions showed a white color and homogeneity, indicating that all the oil was emulsified during the preparation. The emulsions stabilized by the CNF showed a whitish color, but some samples had oily layers between the visibly gelled structure, indicating an excess of non-emulsified essential oil. These samples are PE-1CNF-12-30-3, PE-1CNF-10-20-3, and PE-1CNF-10-30-7. 
CNC

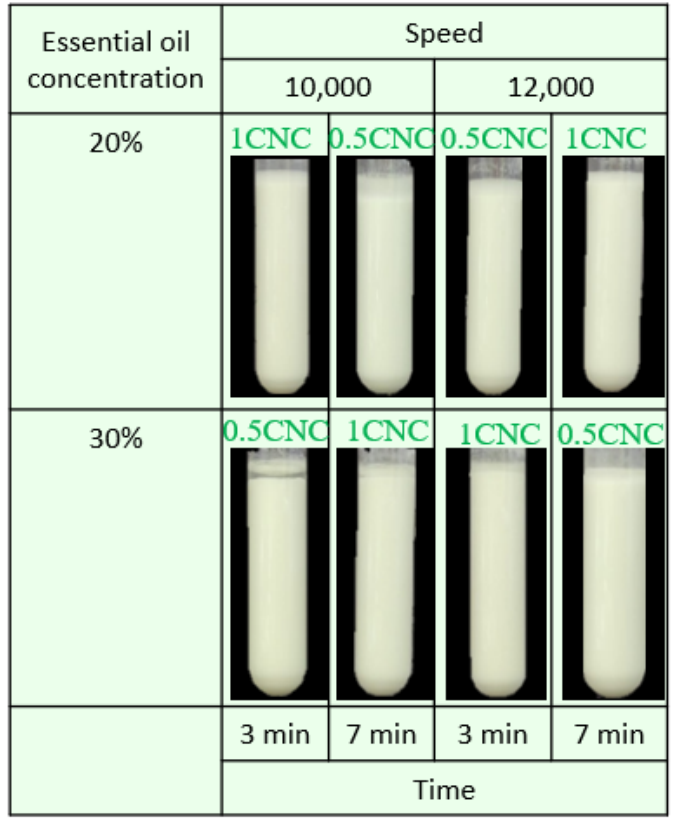

CNF

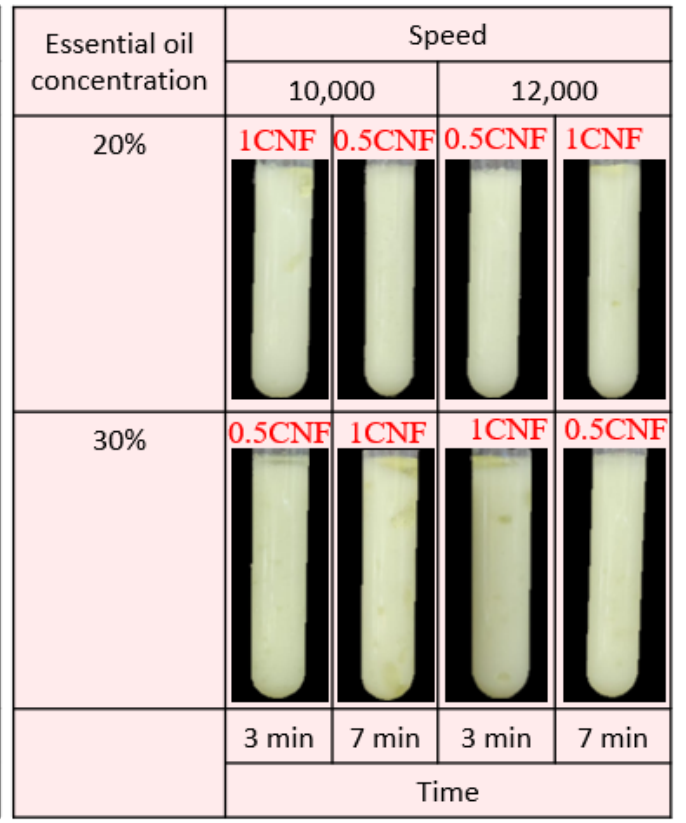

Figure 2. Digital photographs obtained for the essential oil emulsions of cinnamon and water, in different processing parameters, stabilized by CNC or CNF. The green color represents the CNCstabilized emulsions, and the red color represents the CNF-stabilized Pickering emulsions.

\subsection{Particle Size}

Figure $3 a, b$ presents the average droplet sizes of the CNC- and CNF-stabilized emulsions, respectively, measured using optical microscopy. From Figure 3a, the average diameter of all the emulsions ranged from 25 to $50 \mu \mathrm{m}$, while the CNF-stabilized emulsions showed emulsions with larger droplet sizes, varying from 30 to $\sim 100 \mu \mathrm{m}$.
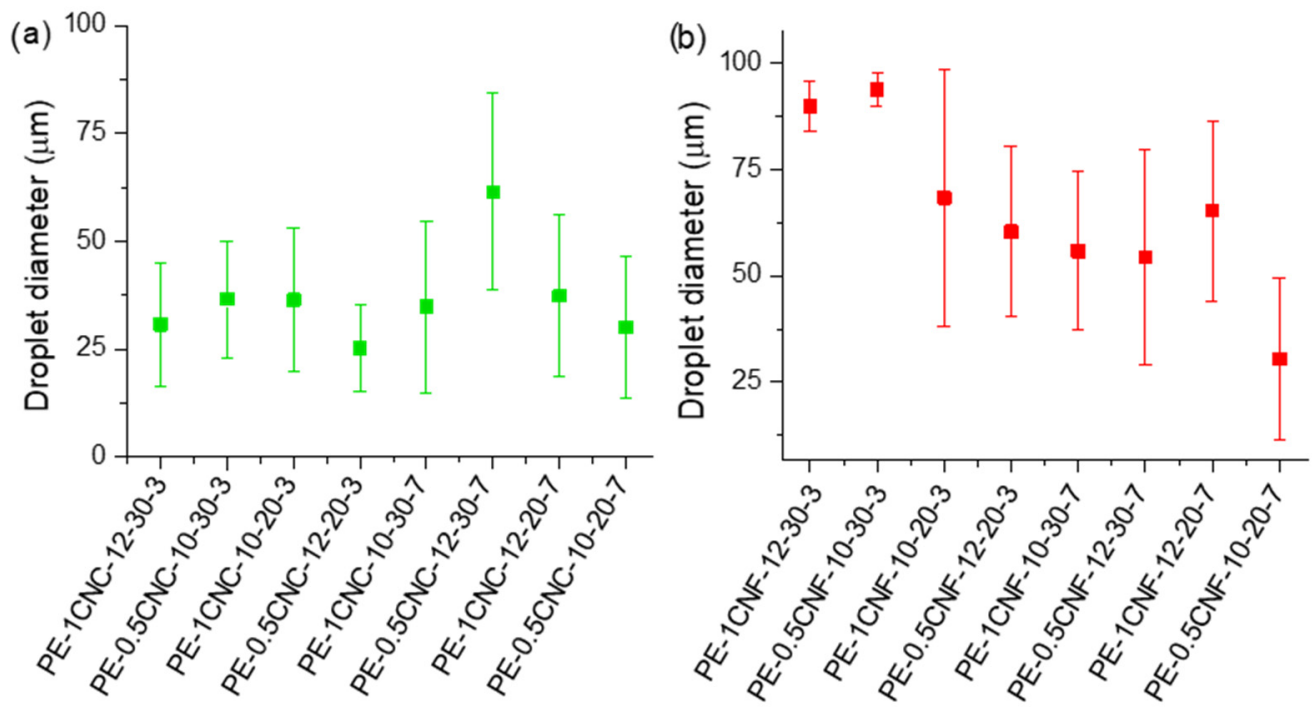

Figure 3. Average droplet diameters obtained for emulsions stabilized by (a) CNC and (b) CNF.

Sample PE-0.5CNC-12-30-7 presented the highest values of drop diameters, indicating that these parameters were not adequate for small droplet formation. This sample is statistically different from the other ones (Table S1), indicating that the diameters are high, possibly due to a low homogenization. Since this sample was prepared with the highest speed, oil concentration, and time, this may be an indication that there was an excess of 
energy, which may not have been beneficial for the emulsions' preparation, and after the preparation, there was droplets coalescence, resulting in phase separation and reflecting in larger drops.

In Figure 3b, samples PE-1CNF-12-30-3 and PE-0.5CNF-10-30-3 were statistically different from the other emulsions with larger droplet sizes (Table S2). These emulsions have the essential oil concentration $(30 \%)$ and preparation time ( $3 \mathrm{~min}$ ) in common, and the larger droplet sizes indicate that at high oil concentrations, greater energy is required to dissociate oil droplets. In addition, the high concentration of essential oil may be a limiting factor for stabilization using CNFs, since there is an OE limit capable of being effectively stabilized without excess or the tendency to coalescence. Zhai et al. [45] tested different peanut oil concentrations stabilized by bacterial cellulose nanofibers and observed that $25 \%$ is the best oil concentration. The authors reported that the particles could be adsorbed at the oil/water interface, generating a surface layer with nanofibers that prevent droplet coalescence. Moreover, sample PE-0.5CNF-10-20-7 showed smaller droplet sizes, which are associated with emulsion stability.

\subsection{Morphology}

Figure 4 a shows the optical microscopy images obtained for CNC-stabilized cinnamon emulsions. It is possible to observe the spherical drops and small sizes distributed homogeneously. In addition, small white dots are identifiable in some images, indicating tiny stable droplets. The drops in larger sizes were identified in a state separate from the others, which, according to Chen et al. [46], is not a flocculation trend and represents that even with larger droplet sizes, the emulsion is stable, and the diameters are associated with insufficient energy to break all the droplets into smaller droplets. This stability that keeps the drops away from each other is probably due to electrostatic forces resulting from the coating of oil droplets by CNCs, which cause the repulsion of the droplets to each other due to the negative charges resulting from CNC-free hydroxyls [47].

Figure 4 b shows the optical microscopy images obtained for CNF-stabilized cinnamon emulsions. The emulsions presented an entirely different morphology from that observed in Figure 4a, with a gel layer, opaque and irregular, easily distinguishable just below the drops.

Samples PE-1CNF-12-30-3, PE-1CNF-10-30-7, and PE-0.5CNF-10-20-7 showed larger and closer drops to each other and packaged, indicating a possible coalescence [48]. However, according to Lu et al. [18], this behavior is observed in the emulsions stabilized with anisotropic particles and is related to "network organization", in which the drops seek their thermodynamically favorable state of the organization. We obtained separated and well-distinguished droplets in this work, reflecting the steric repulsion and physical stability generated by the CNFs. Yuan et al. [49] used cellulosic fibers to stabilize the emulsions and obtained large particle clusters. 

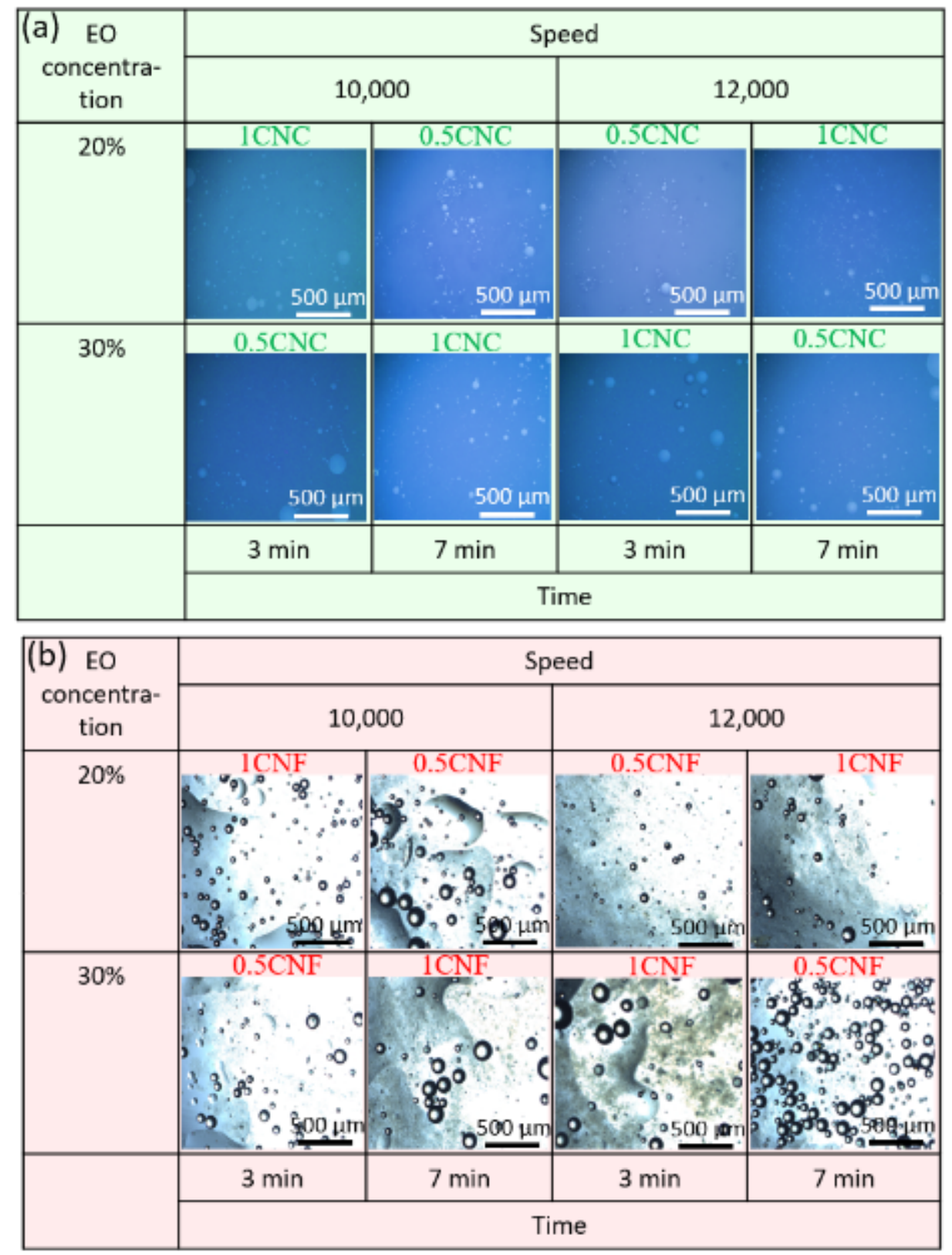

Figure 4. Representative photomicrographs obtained using optical microscopy of cinnamon and water emulsions stabilized with (a) CNC (green), and (b) CNF (red).

\subsection{Stability over Storage Time}

Figure 5 shows the digital photograph (physical stability) of all the developed emulsions stabilized with CNCs at days 0 and 30 . The fresh samples showed good stability to coalescence, sedimentation, and creaming conditions. 


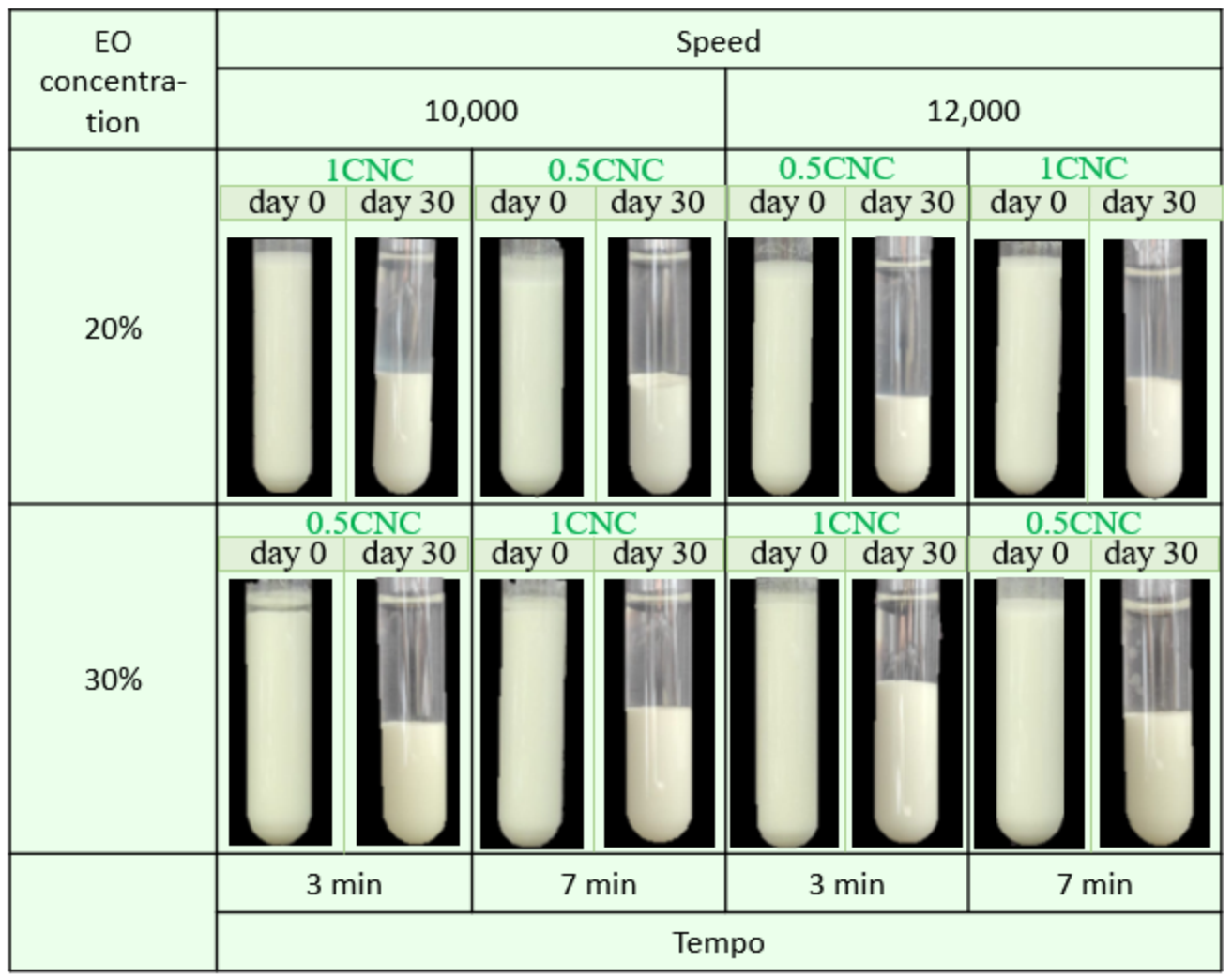

Figure 5. Representative photographs obtained using optical microscopy of cinnamon and water emulsions stabilized with CNC.

After 30 storage days, visible sedimentation occurred, forming a cream layer at the bottom of the tube due to the differences in the density of the two phases [50]. Table 3 shows the creaming index $(\mathrm{CI})$ values of all the emulsions, and a higher $\mathrm{CI}$ indicates a lower physical stability. Samples PE-1CNC-12-30-3 and PE-0.5CNC-12-30-7 showed CI values of 34.4 and $42.8 \%$ after 30 storage days, respectively, being the most stable CNCstabilized samples. Both samples showed the homogenization speed and oil concentration as common parameters between the samples, i.e., in addition to the EO concentration, the energy amount transferred to the system is also an essential factor in emulsion stability.

Table 3. Creaming index values for cinnamon Pickering emulsions stabilized with CNC.

\begin{tabular}{cccccc}
\hline Sample & Day 0 & Day 10 & $\begin{array}{c}\text { CI } \\
\text { Day 15 }\end{array}$ & Day 21 & Day 30 \\
\hline PE-1CNC-12-30-3 & 0 & 30.7 & 33.1 & 33.9 & 34.4 \\
PE-0.5CNC-10-30-3 & 0 & 45.8 & 47.5 & 49.1 & 49.2 \\
PE-1CNC-10-20-3 & 0 & 48.7 & 49.1 & 50.4 & 52.3 \\
PE-0.5CNC-12-20-3 & 0 & 55.8 & 59.2 & 59.4 & 59.5 \\
PE-1CNC-10-30-7 & 0 & 41.1 & 42.7 & 43.4 & 45.3 \\
PE-0.5CNC-12-30-7 & 0 & 41.4 & 41.6 & 42.8 & 42.8 \\
PE-1CNC-12-20-7 & 0 & 45.9 & 48.2 & 49.9 & 52.3 \\
PE-0.5CNC-10-20-7 & 0 & 50.1 & 54.0 & 55.2 & 55.6 \\
\hline
\end{tabular}

Figure 6 shows the digital photograph (physical stability) of all the developed emulsions stabilized with CNFs at days 0 and 30 . 


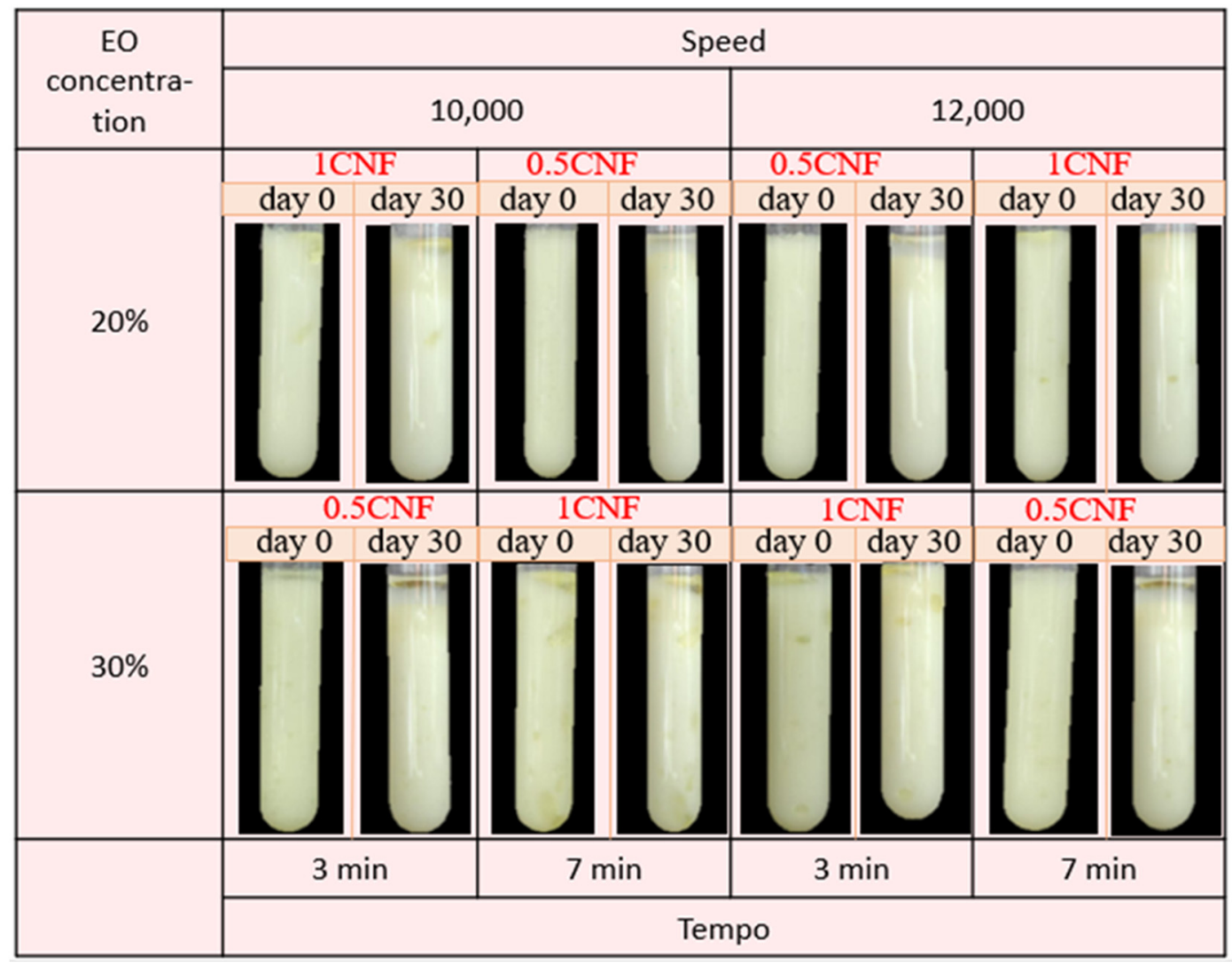

Figure 6. Representative photographs obtained using optical microscopy of cinnamon and water emulsions stabilized with CNF.

Unlike the CNC-stabilized emulsions, the CNF-stabilized emulsions presented a gellike aspect due to the cellulose nanofibers' self-assembling characteristic that tends to form a porous three-dimensional network. The porous structure "encapsulates" the oil drops, preventing the coalescence and flocculation phenomena. All the cinnamon emulsions showed 100\% stability after 30 days of storage, confirming the high long-term stabilization potential of the prepared Pickering emulsions.

Although all the samples are $100 \%$ stable, i.e., do not show creaming or sedimentation, samples PE-1CNF-12-30-3, PE-1CNF-10-20-3, and PE-1CNF-10-30-7 presented visually perceptible free oil inside the test tube, indicating that these samples were not homogeneously emulsified. Moreover, samples PE-0.5CNF-10-30-3, PE-1CNF-10-30-7, and PE-0.5CNF-1230-7 presented a thin surface oil layer on the top, indicating that during the 30 storage days, a part of the oil was unfastened and coalesced.

Based on the results presented, the most stable samples were PE-0.5CNF-12-20-3 and PE-1CNF-12-20-7, having the lowest essential oil content (opposite of that observed for cellulose nanocrystals) and higher rotation in common.

\subsection{Design of Experiments}

An ANOVA was used for the Reduced 2FI model, and an $\mathrm{R}^{2}$ of 0.98 and 0.97 were obtained for the creaming and droplet size, respectively. Figure S1 presents the response surface graphs obtained for the creaming index of CNC-stabilized cinnamon emulsions, generated using software Design Expert 11. The graphs allow for the identification that in emulsions stabilized with CNC, the preparation pattern is the concentration of $30 \%$ of oil and the homogenization speed of 12,000 rpm. This analysis was also performed for droplet size, as shown in Figure S2. Analyzing the data, the most promising samples in terms of stability and particle size were PE-1CNC-12-30-3 and PE-0.5CNC-12-30-7. These samples possibly presented better interfacial coating by rigid cellulose nanoparticles. The lower 
CNC concentration required a longer preparation time, and the higher the concentration was, the shorter the required amount of time was. For the higher concentration CNCs, the emulsions reached an equilibrium time of $3 \mathrm{~min}$, and additional times do not alter the dispersion state since the energy input is too low to promote more deformation and particle breakage. In lower concentrations, more time was needed to achieve this state of equilibrium [51].

Figure S3 presents the response surface graphs obtained for the droplet size of CNFstabilized cinnamon emulsions. The graphs indicated that lower essential oils concentrations resulted in particles with smaller diameters, the opposite of that observed for CNC-stabilized emulsions. This behavior variation between CNCs and CNFs can be associated with a difference in the viscosity and the flow of emulsions, which results in a variation in particle dispersion. Kempin et al. reported that previously there had been no influence of emulsion volume and its phases on drop size distribution, indicating that this behavior is an innovative discovery for cinnamon essential oil [51]. Another parameter that tended to lower particle sizes were higher rotation, similar to that observed for the emulsions stabilized by CNCs, indicating that the cinnamon essential oil requires a higher homogenization speed, i.e., higher energies to achieve an efficient dispersion of the drops, and consequently, the breakdown of the oily phase into smaller droplets. The CNF-stabilized emulsions that stood out were PE-0.5CNF-12-20-3 and PE-1CNF-12-20-7.

From the ANOVA results, the ultimate equations for the creaming index (Equation (3)) and droplet size (Equation (4)) concerning coded factors (A: particle concentration, B: oil concentration, C: speed, D: time, and E: nanocellulose morphology) were obtained.

$$
\begin{gathered}
\mathrm{CI}=74.4-1.42 \cdot \mathrm{A}-3 \cdot \mathrm{B}-0.83 \cdot \mathrm{C}+0.03 \cdot \mathrm{D}+25.5 \cdot \mathrm{E}-0.11 \cdot \mathrm{AB}-0.52 \cdot \mathrm{AC}+ \\
1.33 \cdot \mathrm{AD}+1.43 \cdot \mathrm{AE}+3.0 \cdot \mathrm{BE}+0.84 \cdot \mathrm{CE}-0.03 \cdot \mathrm{DE} \\
\text { Droplet size }=+52.8-0.86 \cdot \mathrm{A}+4.3 \cdot \mathrm{B}-3.5 \cdot \mathrm{C}-2.1 \cdot \mathrm{D}+11.3 \cdot \mathrm{E}+0.84 \cdot \mathrm{AB}+ \\
5.08 \cdot \mathrm{AC}-2.33 \cdot \mathrm{AD}+2.46 \cdot \mathrm{AE}+6.78 \cdot \mathrm{BE}+3.64 \cdot \mathrm{CE}-6.19 \cdot \mathrm{DE}
\end{gathered}
$$

The individual parameters that influenced the emulsion creaming layer, and consequently, their instability, were time and nanocellulose morphology, while the droplet size was affected by oil concentration, which was a constant in the selected emulsions. Considering the parameters' interactions in pairs, the particle concentration and morphology were highly affected by all the others, i.e., the solid phase characteristic is an essential parameter that should be considered to obtain a stable emulsion without phase separation. By ignoring the nanocellulose morphology, since both morphologies were investigated in this work, the nanocellulose concentration showed a high dependency on the other factors for all the emulsions.

Figure 7 shows a schematic illustration compiled from the main information and results of the final formulations selected. Figure 7 was divided considering cellulose morphologies, where the green rectangle represents CNC-stabilized emulsions, and the red one represents the CNF-emulsions. The selected emulsions based on the previously discussed results were presented with their respective appearance and optical microscopies. Moreover, the stabilization mechanism of each emulsion was illustrated: an electrostatic mechanism for CNC, based on solid rigid particles with low L/D and oil droplets repulsion, and steric mechanism for CNF-emulsions, based on the formation of a three-dimensional network resulting from cellulose nanofibers entanglements and oil droplets entrapped inside the CNF network. Both systems showed the same oil concentration and homogenization speed for the optimum samples, considering the CNC or CNF-emulsion pairs. 

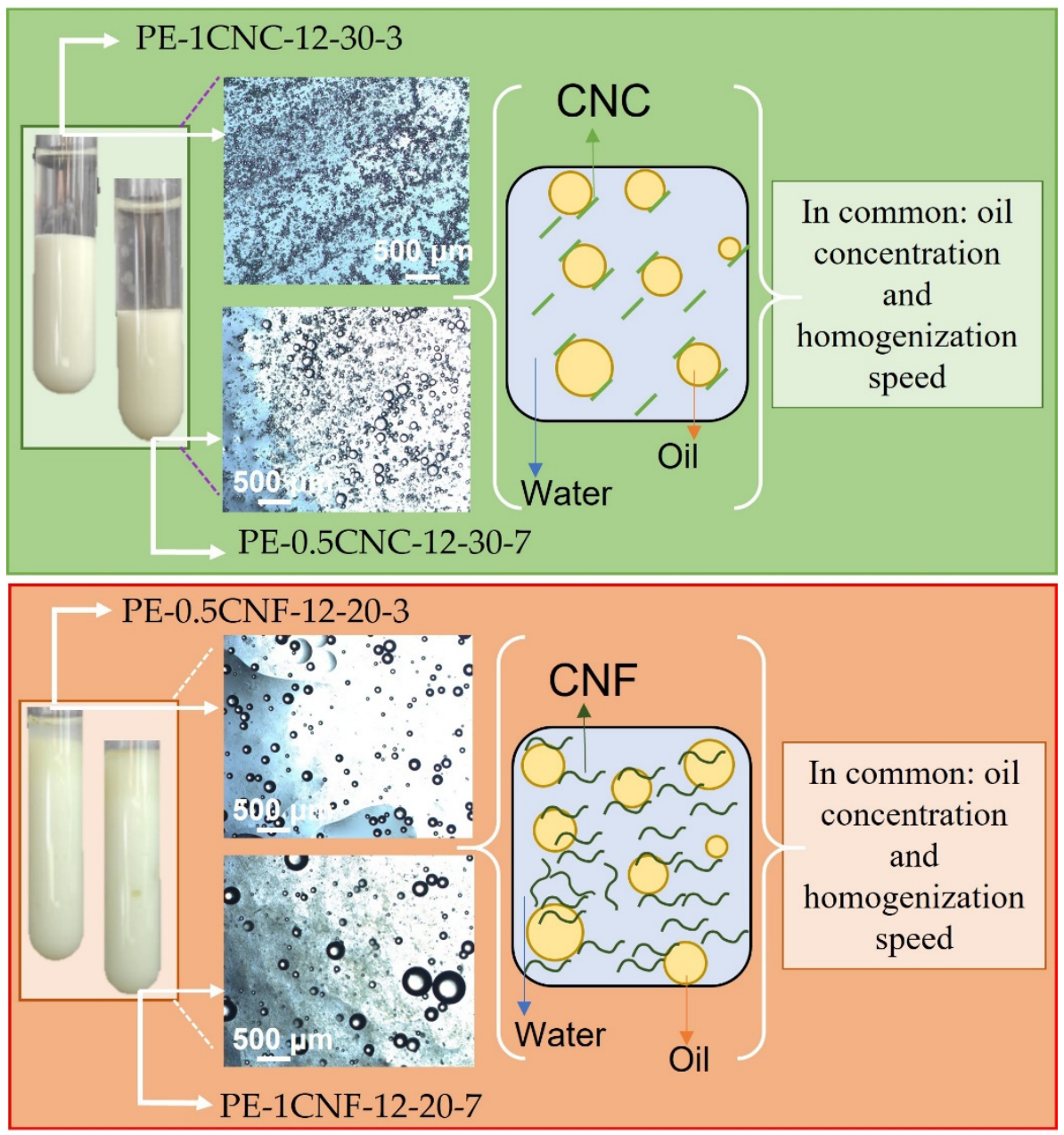

Figure 7. Schematic illustration of the main results and final formulation of cinnamon Pickering emulsions stabilized with CNC and CNF.

\subsection{Final Formulations}

As shown in Figure 8, based on particle size and physical stability, the samples PE1CNC-12-30-3, PE-0.5CNC-12-30-7, PE-0.5CNF-12-20-3, and PE-1CNF-12-20-7 were selected to evaluate the properties of the emulsions, i.e., stability toward shear, zeta potential, and antimicrobial activity.

\subsubsection{Stability toward Shear}

The stability toward shear is related to the interactions between the phases present in the system (essential oil, water, and nanoparticles) and the presence of agglomerates, which can be segregated into separate units, forming larger clusters or droplets aggregated by coalescence $[35,42]$. Figure 8 shows the emulsions after centrifugation to evaluate the stability of the samples. After centrifugation, there was no separation of the phase, sedimentation, or creamy phase fraction, indicating that the emulsions remained stable, even with high shear. Similar results were reported by Gestranius et al. [12], confirming the efficiency of nanocellulosic materials as Pickering emulsion stabilizers. 


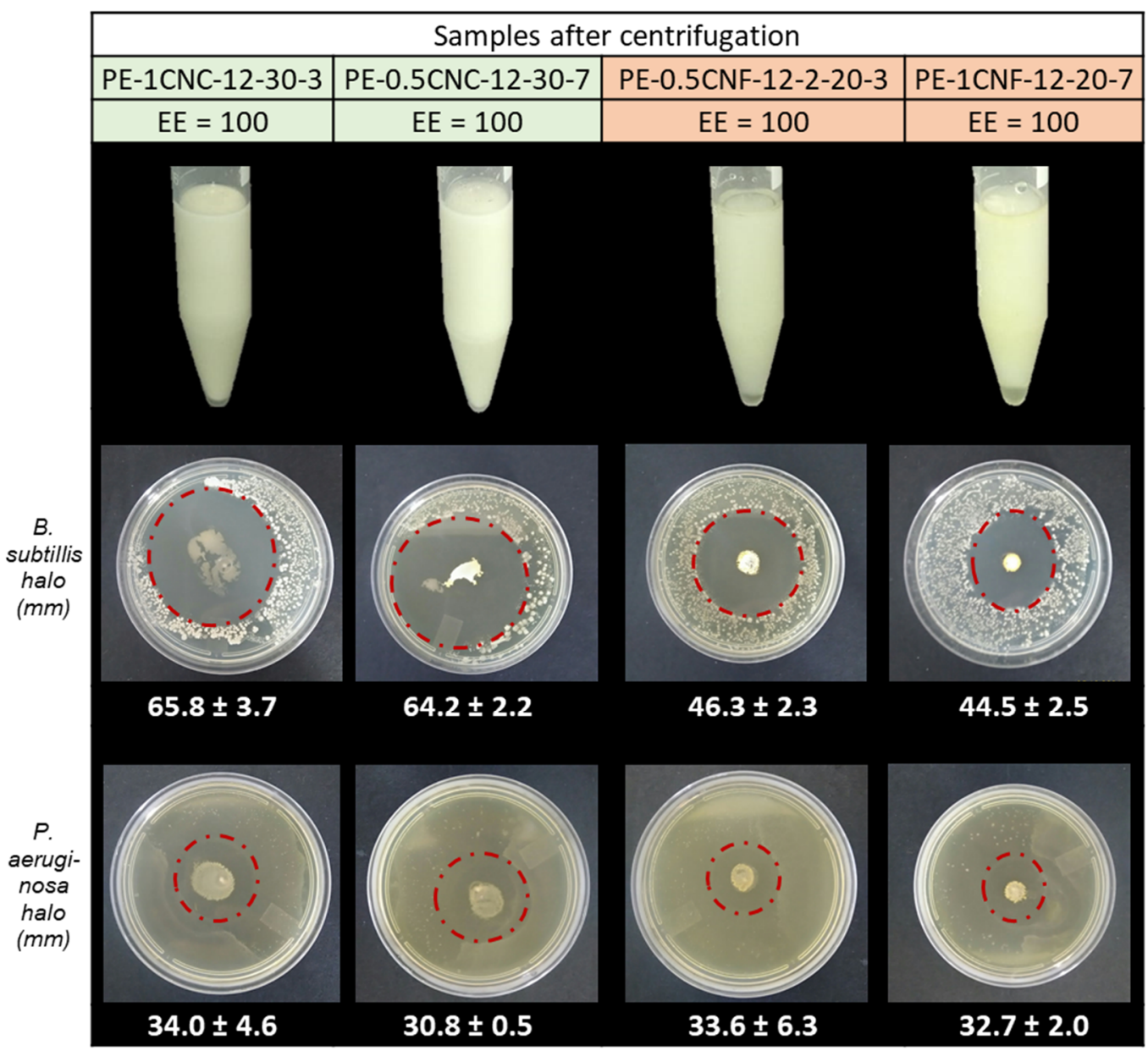

Figure 8. Emulsions after centrifugation to assess stability toward shear, followed by their inhibition halos obtained against the Gram-positive B. subtilis and Gram-negative P. aeruginosa. The green color represents the CNC-stabilized emulsions, and the red color represents the CNF-stabilized Pickering emulsions.

\subsubsection{Zeta Potential}

The Zeta potential values of PE-1CNC-12-30-3 and PE-0.5CNC-12-30-7 were $-29.3 \pm 3.9$ and $-28.3 \pm 1.7$, respectively. The $\zeta$ potential values are associated with the surface groups' ionization, small molecules or ion adsorption, the continuous charges associated with crystalline structures, or the combined mechanisms [52]. The first emulsion was prepared with $1 \%$ CNC and the second with $0.5 \%$ solid phase, and both have the same concentration of essential oil; the difference in the $\zeta$ potential values can be attributed to the availability of CNC-free hydroxyls. However, as the values were remarkably similar, it is correct to affirm that both emulsions showed similar colloidal stability governed by electrostatic forces. Shao et al. [53] prepared cinnamaldehyde emulsions stabilized with Ulva fasciata, a natural polysaccharide, and found $\zeta$ potential values between -26 and $-38 \mathrm{mV}$, depending on the solid phase concentration. According to the authors, the particles increased the emulsion negative surface charges, increasing the system's electrostatic charges and repulsive forces, resulting in a stabilized Pickering emulsion. These Zeta potential results demonstrate that the nanocellulose concentration did not impact electrostatic stability, i.e., for cinnamon essential oil, under appropriate process conditions (12,000 rpm and 30\% oil), a low CNCs concentration is sufficient to generate a physically stable system.

The $\zeta$ potential values of PE-0.5CNF-12-20-3 and PE-1CNF-12-20-7 were $-18.3 \pm 1.4$ and $-11.1 \pm 0.9$, respectively. Stabilization with cellulose nanofibers resulted in low zeta potential values, indicating that the emulsion's electrostatic charge is low. These values were expected because the nanofibers are organized in a three-dimensional network, as pre- 
viously presented, and prevent oil drops from approaching through physical impediment, i.e., steric stabilization. He et al. [54] prepared emulsions using Flammulina velutiper fibers as stabilizers and found $\zeta$ potential values similar to that found in this study. The authors reported that emulsions in steric stabilized by the electrostatic charges are less influential for emulsion stability. The negative values may be associated with the CNFs adsorbed on the oil drops' surface, leading to the formation of a thicker interfacial layer, which altered the location of the effective shear plane where the zeta potential is measured [55]. Different from that observed for emulsions stabilized by CNCs, the emulsions containing CNF showed differences in their zeta potential values for the different concentrations of solid particles, and the sample containing 1\% CNF presented the lowest absolute value. This result may indicate that the highest CNF concentration was necessary for forming the interfacial layer to ensure good stability.

\subsubsection{Antimicrobial Tests}

The Pickering emulsions' antimicrobial activity was tested against B. subtilis (Grampositive) and P. aeruginosa (Gram-negative). As shown in Figure 8, all the emulsions showed strong inhibitory activity, capable of inhibiting the growth of both Gram-negative and Gram-positive bacteria. Both CNF emulsions against B. subtilis showed halos $30.1 \pm 3.7 \%$ smaller than those found in CNC $(65.8 \pm 3.7$ and $64.2 \pm 2.2 \mathrm{~mm})$ emulsions. The PE-1CNC12-30-3 and PE-0.5CNC-12-30-7 presented the lowest zeta potential values $(\sim-30 \mathrm{mV})$, facilitating the approximation of the emulsion droplets and bacteria, potentiating antimicrobial activity [56]. Moreover, the CNC concentration has no impact on inhibition zone diameters. This result highlights the importance of the screening stage of the emulsion process parameters since the most stable emulsions presented similar characteristics of drop size, physical-chemical properties, and antimicrobial properties, even with different solid-phase concentrations. Huang et al. prepared Cinnamon Cassia emulsions stabilized by chitin nanofibrils and reported a strong influence of solid content on antimicrobial properties [57]. These findings corroborate the discussion made above regarding the nanocellulose morphologies and their interaction with the EOs. Different regulation of the EO migration to the medium is promoted in CNF, since it creates a solid and dense three-dimensional network that results in a more tortuous path to the oils than the CNC [31,44], reducing the oil volatility, preventing its rapid release to the environment, and, consequently, influencing the inhibitory concentration of the EOs in the medium.

$P$. aeruginosas' inhibition zone diameters were lower than those observed for $B$. subtilis and similar for the CNC- and CNF-stabilized emulsions. This notorious difference indicates that the migration ratio does not affect the Gram-negative bacteria as it does for the less resistant Gram-positive species [58].

\section{Future Perspectives}

Recently, there has been an increasing demand for the application of Pickering emulsions in various industries due to their combined advantage in terms of cost, quality, and sustainability. Pickering Emulsions (PEs) stand out due to their considerably higher creep resistance than conventional emulsions due to the irreversible adsorption of solid particles at the interfaces of two immiscible liquids [59]. In addition to its excellent advantages in terms of stability over time, the demand for new, non-toxic, and environmentally friendly solid particles has emerged as an innovative solution to allow for the application of Pickering emulsions in various fields, such as food, packaging, cosmetics, the recovery of oil, drug delivery, and others. Various solid particles can be used in Pickering emulsions, and the resulting emulsions have some excellent benefits such as good mechanical attributes, high stability, less toxicity, less foaming problems. Among the particles that can be used, environmentally friendly particles stand out, especially polysaccharides, such as starch, chitin, gelatin, proteins, and nanocellulose $[15,19,22,60,61]$. The reasons behind the growing interest in cellulose-based particle-stabilized emulsions are not only their low cost, readily 
available, safe, and sustainable natural characteristics, but also the fact that they are readily accessible to physical or chemical modification and have a low risk of toxicity.

Nanocellulose is a versatile material with a high surface area and varying proportions depending on its morphology. These multifunctional nanomaterials are mainly found as nanocrystals (CNC) or nanofibers (CNF), and the morphology directly impacts the type of emulsion stabilization. The adsorption process of nanocellulose at the oil and water interface is related to the diffusion of particles through the liquid and their positioning on the interfaces, which depend on the chemical parameters and the surface charges. Its use has been widely reported, mainly to stabilize essential oils with bactericidal activities. In their stabilized form, essential oils are an excellent choice for use in active packaging, as they have antibacterial and antifungal properties [62-64]. The development of intelligent films for pharmaceutical, food, and cosmetic applications aims to improve functional properties such as drug delivery and mechanical and barrier properties, while increasing safety concerns $[65,66]$. Thus, the emulsions developed in this work have a high potential for applying highly efficient antimicrobial products, a growing demand by the consumer market.

\section{Conclusions}

This work investigated the cinnamon emulsification process using the Pickering emulsion approach with nanocellulose as a solid phase. The processing parameters and cellulose morphology and concentration were varied to investigate their influence on emulsion stabilization. The CNC-stabilized emulsions showed spherical droplets with average diameters between 25 and $50 \mu \mathrm{m}$. After 30 storage days, CNC emulsions showed a cream layer at the bottom of the tubes, and the most stable samples showed a creaming index of 34.4 and $42.8 \%$; the homogenization speed $(12,000 \mathrm{rpm})$ and oil concentration $(30 \%)$ were standard parameters, indicating a pattern for CNC-stabilized emulsions. The CNF-stabilized emulsions showed spherical droplets with average diameters between 30 and $100 \mu \mathrm{m}$, without phase separation after 30 storage days. The gel-like aspect, formed due to the cellulose nanofibers' self-assembling characteristic, resulted in high stability, and the standard parameters of stable emulsions were the homogenization speed $(12,000 \mathrm{rpm})$ and oil concentration (20\%). The final formulations showed $100 \%$ stability toward shear, without sedimentation after centrifugation, and the zeta potential confirmed the stabilization mechanism of each nanocellulose, i.e., electrostatic for CNC-emulsions and steric for CNF-based emulsions. Both CNC- and CNC-stabilized emulsions present an inhibition effect against Gram-negative and Gram-positive bacteria, confirming the antimicrobial potential of the Pickering emulsions. This work can act as a template for researchers to understand the influence of Pickering emulsion process parameters and their relationship with solid stabilizers and essential oil, being a guideline for future studies. The reported results showed application potential for an antimicrobial essential oil in several products and industries.

Supplementary Materials: The following are available online at https://www.mdpi.com/article/ 10.3390/polysaccharides2030037/s1, Table S1: Tukey test for CNC-stabilized emulsions for droplet sizes of fresh emulsions. Table S2: Tukey test for CNF-stabilized emulsions for droplet sizes of fresh emulsions. Figure S1: Effects of parameters processing on the emulsions creaming index, analyzed using response surface plots. Figure S2: Effects of parameters processing on the emulsion's droplet size, analyzed using response surface plots. Figure S3: Effects of parameters processing on the emulsion's droplet size, analyzed using response surface plots.

Author Contributions: Conceptualization, A.G.d.S. and E.S.F.A.; methodology, A.G.d.S., R.R.F., E.S.F.A. and L.Z.; validation, A.G.d.S., R.R.F., E.S.F.A. and L.Z.; formal analysis, A.G.d.S.; investigation, A.G.d.S.; resources, D.d.S.R.; data curation, A.G.d.S.; writing—original draft preparation, A.G.d.S., R.R.F. and L.Z.; writing-review and editing, A.G.d.S.; L.Z. and D.d.S.R.; visualization, A.G.d.S. and D.d.S.R.; supervision, D.d.S.R.; project administration, A.G.d.S. and D.d.S.R.; funding acquisition, D.d.S.R. All authors have read and agreed to the published version of the manuscript. 
Funding: This research was funded by Conselho Nacional de Desenvolvimento Científico e Tecnológico (305819/2017-8) and Fundação de Amparo à Pesquisa do Estado de São Paulo (2018/11277-7).

Institutional Review Board Statement: Not applicable.

Informed Consent Statement: Not applicable.

Acknowledgments: The authors thank the UFABC, CAPES (Code 001), and REVALORES Strategic Unit. The authors are grateful to the multiuser central facilities (UFABC) for the experimental support.

Conflicts of Interest: The authors declare no conflict of interest.

\section{References}

1. Becerril, R.; Nerín, C.; Silva, F. Encapsulation Systems for Antimicrobial Food Packaging Components: An Update. Molecules 2020, 25, 1134. [CrossRef] [PubMed]

2. Bahrami, A.; Delshadi, R.; Assadpour, E.; Jafari, S.M.; Williams, L. Antimicrobial-Loaded Nanocarriers for Food Packaging Applications. Adv. Colloid Interface Sci. 2020, 278, 102140-102153. [CrossRef] [PubMed]

3. Das, S.; Horváth, B.; Šafranko, S.; Jokić, S.; Széchenyi, A.; Koszegi, T. Antimicrobial Activity of Chamomile Essential Oil: Effect of Different Formulations. Molecules 2019, 24, 4321. [CrossRef] [PubMed]

4. Krepker, M.; Shemesh, R.; Danin Poleg, Y.; Kashi, Y.; Vaxman, A.; Segal, E. Active Food Packaging Films with Synergistic Antimicrobial Activity. Food Control 2017, 76, 117-126. [CrossRef]

5. Rudra, S.G.; Gundewadi, G. Natural Additives with Antimicrobial and Flavoring Potential for Fresh-Cut Produce. In Fresh-Cut Fruits and Vegetables; Elsevier Inc.: Amsterdam, The Netherlands, 2020; pp. 165-182.

6. Ashokkumar, K.; Murugan, M.; Dhanya, M.K.; Warkentin, T.D. Botany, Traditional Uses, Phytochemistry and Biological Activities of Cardamom [Elettaria cardamomum (L.) Maton]_A Critical Review. J. Ethnopharmacol. 2020, 246, 112244. [CrossRef]

7. Silva e Silva Figueiredo, C.S.; Viera de Oliveira, P.; De Silva Saminez, W.F.; Muniz Diniz, R.; Silva Rodrigues, J.F.; Maia da Silva, M.S.; Nascimento da Silva, L.C.; Grigolin Grisotto, M.A. Óleo Essencial da Canela (Cinamaldeído) e Suas Aplicações Biológicas. Rev. Investig. Bioméd. 2018, 9, 192-197. [CrossRef]

8. Zhang, C.; Fan, L.; Fan, S.; Wang, J.; Luo, T.; Tang, Y.; Chen, Z.; Yu, L. Cinnamomum cassia Presl: A Review of its Traditional Uses, Phytochemistry, Pharmacology and Toxicology. Molecules 2019, 24, 3473. [CrossRef] [PubMed]

9. Jiang, Y.; Dan, W.; Feng, L.; Li, D.; Huang, Q. Cinnamon Essential Oil Pickering Emulsion Stabilized by Zein-Pectin Composite Nanoparticles: Characterization, Antimicrobial Effect and Advantages in Storage Application. Int. J. Biol. Macromol. 2019. [CrossRef] [PubMed]

10. Tung, Y.T.; Yen, P.L.; Lin, C.Y.; Chang, S.T. Anti-Inflammatory Activities of Essential Oils and their Constituents from Different Provenances of Indigenous Cinnamon (Cinnamomum osmophloeum) Leaves. Pharm. Biol. 2010, 48, 1130-1136. [CrossRef] [PubMed]

11. Vasconcelos, N.G.; Croda, J.; Simionatto, S. Antibacterial Mechanisms of Cinnamon and its Constituents: A Review. Microb. Pathog. 2018, 120, 198-203. [CrossRef]

12. Gestranius, M.; Stenius, P.; Kontturi, E.; Sjöblom, J.; Tammelin, T. Phase Behaviour and Droplet Size of Oil-in-Water Pickering Emulsions Stabilised with Plant-Derived Nanocellulosic Materials. Colloids Surf. A Physicochem. Eng. Asp. 2017, 519, 60-70. [CrossRef]

13. Razavi, M.S.; Golmohammadi, A.; Nematollahzadeh, A.; Fiori, F.; Rovera, C.; Farris, S. Preparation of Cinnamon Essential Oil Emulsion by Bacterial Cellulose Nanocrystals and Fish Gelatin. Food Hydrocoll. 2020, 109, 106111. [CrossRef]

14. Vis, M.; Opdam, J.; Vant Oor, I.S.J.; Soligno, G.; Van Roij, R.; Tromp, R.H.; Erné, B.H. Water-in-Water Emulsions Stabilized by Nanoplates. ACS Macro Lett. 2015, 4, 965-968. [CrossRef]

15. Ben Cheikh, F.; Mabrouk, A.B.; Magnin, A.; Putaux, J.-L.; Boufi, S. Chitin Nanocrystals as Pickering Stabilizer for O/W Emulsions: Effect of the Oil Chemical Structure on the Emulsion Properties. Colloids Surf. B Biointerfaces 2021, 200, 111604. [CrossRef] [PubMed]

16. Briggs, N.M.; Weston, J.S.; Li, B.; Venkataramani, D.; Aichele, C.P.; Harwell, J.H.; Crossley, S.P. Multiwalled Carbon Nanotubes at the Interface of Pickering Emulsions. Langmuir 2015, 31, 13077-13084. [CrossRef]

17. Tang, C.; Chen, Y.; Luo, J.; Low, M.Y.; Shi, Z.; Tang, J.; Zhang, Z.; Peng, B.; Tam, K.C. Pickering Emulsions Stabilized by Hydrophobically Modified Nanocellulose Containing Various Structural Characteristics. Cellulose 2019, 26, 7753-7767. [CrossRef]

18. Lu, Y.; Li, J.; Ge, L.; Xie, W.; Wu, D. Pickering Emulsion Stabilized with Fibrous Nanocelluloses: Insight into Fiber FlexibilityEmulsifying Capacity Relations. Carbohydr. Polym. 2021, 255, 117483. [CrossRef]

19. Yan, X.; Ma, C.; Cui, F.; McClements, D.J.; Liu, X.; Liu, F. Protein-Stabilized Pickering Emulsions: Formation, Stability, Properties and Applications in Foods. Trends Food Sci. Technol. 2020, 103, 293-303. [CrossRef]

20. Peddireddy, K.R.; Nicolai, T.; Benyahia, L.; Capron, I. Stabilization of Water-in-Water Emulsions by Nanorods. ACS Macro Lett. 2016, 5, 283-286. [CrossRef]

21. Chen, W.; Yu, H.; Lee, S.-Y.; Wei, T.; Li, J.; Fan, Z. Nanocellulose: A Promising Nanomaterial for Advanced Electrochemical Energy Storage. Chem. Soc. Rev. 2018, 47, 2837-2872. [CrossRef] [PubMed]

22. Saffarionpour, S. Nanocellulose for Stabilization of Pickering Emulsions and Delivery of Nutraceuticals and its Interfacial Adsorption Mechanism. Food Bioprocess Technol. 2020. [CrossRef] 
23. Silva, C.E.P.; Tam, K.C.; Bernardes, J.S.; Loh, W. Double Stabilization Mechanism of O/W Pickering Emulsions Using Cationic Nanofibrillated Cellulose. J. Colloid Interface Sci. 2020, 574, 207-216, submitted. [CrossRef] [PubMed]

24. Thomas, B.; Raj, M.C.; Athira, K.B.; Rubiyah, M.H.; Joy, J.; Moores, A.; Drisko, G.L.; Sanchez, C. Nanocellulose, a Versatile Green Platform: From Biosources to Materials and Their Applications. Chem. Rev. 2018, 118, 11575-11625. [CrossRef]

25. Sanchez-Salvador, J.L.; Balea, A.; Monte, M.C.; Blanco, A.; Negro, C. Pickering Emulsions Containing Cellulose Microfibers Produced by Mechanical Treatments as Stabilizer in the Food Industry. Appl. Sci. 2019, 9, 359. [CrossRef]

26. Mikulcová, V.; Bordes, R.; Kašpárková, V. On the Preparation and Antibacterial Activity of Emulsions Stabilized with Nanocellulose Particles. Food Hydrocoll. 2016, 61, 780-792. [CrossRef]

27. Wang, Y.; Wang, W.; Jia, H.; Gao, G.; Wang, X.; Zhang, X.; Wang, Y. Using Cellulose Nanofibers and Its Palm Oil Pickering Emulsion as Fat Substitutes in Emulsified Sausage. J. Food Sci. 2018, 83, 1740-1747. [CrossRef] [PubMed]

28. Liu, Z.; Lin, D.; Shen, R.; Yang, X. Bacterial Cellulose Nanofibers Improved the Emulsifying Capacity of Soy Protein Isolate as a Stabilizer for Pickering High Internal-Phase Emulsions. Food Hydrocoll. 2021, 112, 106279. [CrossRef]

29. Dong, H.; Ding, Q.; Jiang, Y.; Li, X.; Han, W. Pickering Emulsions Stabilized by Spherical Cellulose Nanocrystals. Carbohydr. Polym. 2021, 265, 118101. [CrossRef]

30. Yu, H.; Huang, G.; Ma, Y.; Liu, Y.; Huang, X.; Zheng, Q.; Yue, P.; Yang, M. Cellulose Nanocrystals Based Clove Oil Pickering Emulsion for Enhanced Antibacterial Activity. Int. J. Biol. Macromol. 2021, 170, 24-32. [CrossRef] [PubMed]

31. Shin, J.; Na, K.; Shin, S.; Seo, S.M.; Youn, H.J.; Park, I.K.; Hyun, J. Biological Activity of Thyme White Essential Oil Stabilized by Cellulose Nanocrystals. Biomolecules 2019, 9, 799. [CrossRef] [PubMed]

32. Seo, S.M.; Lee, J.W.; Shin, J.; Tak, J.H.; Hyun, J.; Park, I.K. Development of Cellulose Nanocrystal-Stabilized Pickering Emulsions of Massoia and Nutmeg Essential Oils for the Control of Aedes Albopictus. Sci. Rep. 2021, 11, 1-12. [CrossRef] [PubMed]

33. Lima, G.F.; Souza, A.G.; Rosa, D.S. Effect of Adsorption of Polyethylene Glycol (PEG), in Aqueous Media, to Improve Cellulose Nanostructures Stability. J. Mol. Liq. 2018, 268, 415-424. [CrossRef]

34. Souza, A.G.; Lima, G.F.; dos Santos Rosa, D. Cellulose Nanostructures from Lignocellulosic Residues; LAP LAMBERT Academic Publishing: Sunnyvale, CA, USA, 2019.

35. Souza, A.G.; Ferreira, R.R.; Paula, L.C.; Setz, L.F.G.; Rosa, D.S. The Effect of Essential Oil Chemical Structures on Pickering Emulsion Stabilized with Cellulose Nanofibrils. J. Mol. Liq. 2020, 320, 114458. [CrossRef]

36. Li, Q.; Xie, B.; Wang, Y.; Wang, Y.; Peng, L.; Li, Y.; Li, B.; Liu, S. Cellulose Nanofibrils from Miscanthus Floridulus Straw as Green Particle Emulsifier for O/W Pickering Emulsion. Food Hydrocoll. 2019, 97. [CrossRef]

37. Ma, Z.; Li, Q.; Wang, B.; Feng, X.; Xu, H.; Mao, Z.; You, C.; Sui, X. Synthetic Semicrystalline Cellulose Oligomers as Efficient Pickering Emulsion Stabilizers. Carbohydr. Polym. 2021, 254, 117445. [CrossRef]

38. Li, Q.; Wang, Y.; Wu, Y.; He, K.; Li, Y.; Luo, X.; Li, B.; Wang, C.; Liu, S. Flexible Cellulose Nanofibrils as Novel Pickering Stabilizers: The Emulsifying Property and Packing Behavior. Food Hydrocoll. 2019, 88, 180-189. [CrossRef]

39. Ahsan, H.M.; Zhang, X.; Li, Y.; Li, B.; Liu, S. Surface Modification of Microcrystalline Cellulose: Physicochemical Characterization and Applications in the Stabilization of Pickering Emulsions. Int. J. Biol. Macromol. 2019, 132, 1176-1184. [CrossRef]

40. Soo, Y.T.; Ng, S.W.; Tang, T.K.; Ab Karim, N.A.; Phuah, E.T.; Lee, Y.Y. Preparation of Palm (Elaeis oleifera) Pressed Fibre Cellulose Nanocrystals via Cation Exchange Resin: Characterisation and Evaluation as Pickering Emulsifier. J. Sci. Food Agric. 2021, 101, 4161-4172. [CrossRef] [PubMed]

41. Luo, J.; Huang, K.; Zhou, X.; Xu, Y. Elucidation of Oil-In-Water Emulsions Stabilized with Celery Cellulose. Fuel 2021, $291,120210$. [CrossRef]

42. Tiong, A.C.Y.; Tan, I.S.; Foo, H.C.Y.; Lam, M.K.; Mahmud, H.B.; Lee, K.T. Macroalgae-Derived Regenerated Cellulose in the Stabilization of Oil-In-Water Pickering Emulsions. Carbohydr. Polym. 2020, 249, 116875. [CrossRef] [PubMed]

43. JIS. JIS (2010) Antibacterial Products-Test for Antibacterial Activity and Efficacy. JIS Z 2801:2010.

44. Camani, P.H.; Torin, R.F.; Souza, C.W.; Zanata, L.; Rosa, D. Antimicrobial Films Containing Hybrid Systems Aiming at Packaging Applications. Polym. Int. 2021, 70, 628-635. [CrossRef]

45. Zhai, X.; Lin, D.; Liu, D.; Yang, X. Emulsions Stabilized by Nanofibers from Bacterial Cellulose: New Potential Food-Grade Pickering Emulsions. Food Res. Int. 2018, 103, 12-20. [CrossRef]

46. Chen, Q.H.; Liu, T.X.; Tang, C.H. Tuning the Stability and Microstructure of Fine Pickering Emulsions Stabilized by Cellulose Nanocrystals. Ind. Crops Prod. 2019, 141, 111733. [CrossRef]

47. Ni, Y.; Li, J.; Fan, L. Production of Nanocellulose with Different Length from Ginkgo Seed Shells and Applications for Oil in Water Pickering Emulsions. Int. J. Biol. Macromol. 2020, 149, 617-626. [CrossRef]

48. Paximada, P.; Tsouko, E.; Kopsahelis, N.; Koutinas, A.A.; Mandala, I. Bacterial Cellulose as Stabilizer of o/w Emulsions. Food Hydrocoll. 2016, 53, 225-232. [CrossRef]

49. Yuan, T.; Zeng, J.; Wang, B.; Cheng, Z.; Chen, K. Pickering Emulsion Stabilized by Cellulosic Fibers: Morphological PropertiesInterfacial Stabilization-Rheological Behavior Relationships. Carbohydr. Polym. 2021, 269, 118339. [CrossRef]

50. Chen, L.; Ao, F.; Ge, X.; Shen, W. Food-Grade Pickering Emulsions: Preparation, Stabilization and Applications. Molecules 2020, 25, 3202. [CrossRef]

51. Kempin, M.V.; Kraume, M.; Drews, A. W/O Pickering Emulsion Preparation Using a Batch Rotor-Stator Mixer-Influence on Rheology, Drop Size Distribution and Filtration Behavior. J. Colloid Interface Sci. 2020, 573, 135-149. [CrossRef] 
52. Cano-Sarmiento, C.; Téllez-Medina, D.I.; Viveros-Contreras, R.; Cornejo-Mazón, M.; Figueroa-Hernández, C.Y.; García-Armenta, E.; Alamilla-Beltrán, L.; García, H.S.; Gutiérrez-López, G.F. Zeta Potential of Food Matrices. Food Eng. Rev. 2018, 10, 113-138. [CrossRef]

53. Shao, P.; Shao, J.; Jiang, Y.; Sun, P. Influences of Ulva Fasciata Polysaccharide on the Rheology and Stabilization of Cinnamaldehyde Emulsions. Carbohydr. Polym. 2016, 135, 27-34. [CrossRef]

54. He, K.; Zhang, X.; Li, Y.; Li, B.; Liu, S. Water-Insoluble Dietary-Fibers from Flammulina Velutiper used as Edible Stabilizers for Oil-In-Water Pickering Emulsions. Food Hydrocoll. 2020, 101, 105519. [CrossRef]

55. Chen, E.; Cao, L.; McClements, D.J.; Liu, S.; Li, B.; Li, Y. Enhancement of Physicochemical Properties of Whey Protein-Stabilized Nanoemulsions by Interfacial Cross-Linking Using Cinnamaldehyde. Food Hydrocoll. 2018, 77, 976-985. [CrossRef]

56. Zhou, Y.; Sun, S.; Bei, W.; Zahi, M.R.; Yuan, Q.; Liang, H. Preparation and Antimicrobial Activity of Oregano Essential Oil Pickering Emulsion Stabilized by Cellulose Nanocrystals. Int. J. Biol. Macromol. 2018, 112, 7-13. [CrossRef]

57. Huang, Y.; Liu, H.; Liu, S.; Li, S. Cinnamon Cassia Oil Emulsions Stabilized by Chitin Nanofibrils: Physicochemical Properties and Antibacterial Activities. J. Agric. Food Chem. 2020, 68, 14620-14631. [CrossRef]

58. Tavares, T.D.; Antunes, J.C.; Padrão, J.; Ribeiro, A.I.; Zille, A.; Amorim, M.T.P.; Ferreira, F.; Felgueiras, H.P. Activity of Specialized Biomolecules against Gram-Positive and Gram-Negative Bacteria. Antibiotics 2020, 9, 314. [CrossRef]

59. Low, L.E.; Siva, S.P.; Ho, Y.K.; Chan, E.S.; Tey, B.T. Recent Advances of Characterization Techniques for the Formation, Physical Properties and Stability of Pickering Emulsion. Adv. Colloid Interface Sci. 2020, 277, 102117. [CrossRef]

60. Zembyla, M.; Murray, B.S.; Sarkar, A. Water-in-Oil Emulsions Stabilized by Surfactants, Biopolymers and/or Particles: A Review. Trends Food Sci. Technol. 2020, 104, 49-59. [CrossRef]

61. Feng, X.; Dai, H.; Ma, L.; Fu, Y.; Yu, Y.; Zhou, H.; Guo, T.; Zhu, H.; Wang, H.; Zhang, Y. Properties of Pickering Emulsion Stabilized by Food-Grade Gelatin Nanoparticles: Influence of the Nanoparticles Concentration. Colloids Surf. B Biointerfaces 2020, 196, 111294. [CrossRef] [PubMed]

62. Nakatsu, T.; Lupo, A.T.; Chinn, J.W.; Kang, R.K.L. Biological Activity of Essential Oils and their Constituents. Stud. Nat. Prod. Chem. 2000, 21, 571-631. [CrossRef]

63. Ribeiro-Santos, R.; Andrade, M.; Sanches-Silva, A.; de Melo, N.R. Essential Oils for Food Application: Natural Substances with Established Biological Activities. Food Bioprocess Technol. 2018, 11, 43-71. [CrossRef]

64. Ribeiro, M.; Simões, L.C.; Simões, M. Biocides. Encycl. Microbiol. 2019, 478-490. [CrossRef]

65. Li, X.; Yang, X.; Deng, H.; Guo, Y.; Xue, J. Gelatin Films Incorporated with Thymol Nanoemulsions: Physical Properties and Antimicrobial Activities. Int. J. Biol. Macromol. 2020, 150, 161-168. [CrossRef] [PubMed]

66. Zhai, X.; Wang, W.; Zhang, H.; Dai, Y.; Dong, H.; Hou, H. Effects of High Starch Content on the Physicochemical Properties of Starch/PBAT Nanocomposite Films Prepared by Extrusion Blowing. Carbohydr. Polym. 2020, 239, 116231. [CrossRef] [PubMed] 